\title{
Season and Age as Factors in Barred Owl (Strix varia) Admissions
}

\author{
Glori Berry, BA \\ AVIAN HAVEN \\ FreEdom, MAINE
}

\begin{abstract}
Barred owl admittance data from Avian Haven, a wildlife rehabilitation facility in central Maine, were examined from April 2005 through March 2011. During this time, 231 barred owls were admitted to the facility, excluding nestlings. A significantly greater number of owls were admitted in the fall and winter months than in the spring and summer months; yearly variations in the fall and winter month admissions also were significant, while those for the spring and summer month admissions were not. Furthermore, a statistically significant proportion of 44 barred owls aged during the 2010/2011 fall/winter season were hatch-year birds, suggesting that yearly variations in barred owl admittance numbers are directly correlated with the number of dispersing hatch-year birds. Finally, in aging the barred owls for this study, a technique using an ultraviolet light source in the form of a black light to examine the fluorescence of porphyrin pigments in the feathers of owls was investigated. It was found to be reliable in differentiating hatch-year owls from adult (after-hatch-year) owls having undergone a partial molt, and has the potential for becoming the definitive method for aging barred owls in a rehabilitation setting.
\end{abstract}

Key words: Aging, barred owl, dispersal, fluorescence, porphyrin

\section{INTRODUCTION}

Barred owls (Strix varia) are territorial year-round residents that usually are found in mixed deciduousconiferous woods (Livezey 2007; Mazur et al 1998; Nicholls and Warner 1972). They are nocturnal predators and a generalist species that eat a variety of prey, from small mammals and birds to amphibians, fish, and invertebrates (Hamer et al 2001; Korschgen and Stuart 1972; Livezey 2007). As fall progresses into winter, the variety of available prey species declines, and throughout winter the owls are more dependent on a selection of small mammals and birds (Hamer et al 2007; Holt and Bitter 2007; Livezey 2007). Small mammals tend to be less accessible when snow covers the ground, which may lead owls to spend more time in search of food, and with the longer search time, exposure to greater risks of vehicular injury (Massemin and Handrich 1997). Adult owls expand their territories during this time, most likely in response to the

Glori Berry is a staff member at Avian Haven, a wildlife rehabilitation facility in Freedom, Maine. She is a former elementary school teacher and plans to attend graduate school in ornithology. more limited food supply (Hamer et al 2007; Livezey 2007; Mazur et al 1998).

Young barred owls are fed by their parents for up to four or five months, at which point the young disperse (Johnsgard 1988; Mazur and James 2000)-just at a time when food is more limited and adults are spreading out (Hamer et al 2007; Livezey 2007; Mazur et al 1998). Because of their inexperience, juvenile birds are at higher risk of injury and death due to predation and accidents compared to adults (Belthoff and Ritchison 1989; Hernandez 1988; Loos and Kerlinger 1993; Postelli 2000).

Dispersing juvenile owls foraging in presumably unfamiliar habitat might be more inclined to make use of snow-free roads as dispersal corridors, especially when small rodent prey species such as mice and voles are attracted to roads because they are clear of snow in the winter (Erritzoe 2002; Massemin and Zorn 1998). Juveniles exposed to cars for the first time may show a higher mortality rate from collisions with vehicles than owls that are more familiar with vehicles (Erritzoe 2002; Hernandez 1988; Loos and Kerlinger 1993; Mead 1997; Ward 1933). Peaks in vehicle collisions occur in the fall, correlating with the dispersal of juveniles of many species (Erritzoe 2002; Loos and Kerlinger 1993; Massemin and Zorn 1998).

Based on the species natural history, it was hypothesized barred owl admissions to rehabilitation are likely to be greater in fall and winter months than in spring and summer months. It was further hypothesized that there would be yearly variations in the fall and winter admissions, depending on factors such as the severity of the winter, but little yearly variation in the spring and summer admissions. A final hypothesis was that juveniles comprise the majority of barred owls admitted during the fall/winter. A corollary to this last hypothesis was that barred owls could be aged reliably via fluorescence of porphyrin pigments in feathers. 


\section{METHOD}

To test the hypotheses regarding seasonal and yearly differences in admissions, records of barred owl cases at Avian Haven (AH), a wildlife rehabilitation facility in central Maine, were examined. For the sake of simplicity, admissions were summed over only two parts of the year-April through September, and October through March. Data were examined for six years, beginning with April-September of 2005, and ending with October-March of 2011. Barred owls admitted as nestlings were excluded from the data set.

In order to test the hypothesis that most of the barred owls admitted to AH during the fall and winter months were juveniles, the individuals had to be aged. There is little published information on the molt of the barred owl, with much of it based on the assumption that it runs a similar course to that of the closely related northern spotted owl (Strix occidentalis) (Howell 2010; Mazur and James 2000; Pyle 1997a; Pyle 1997b). As Pyle stated, when aging a bird, all available information (whether or not it is definitive) should be considered because there are always intermediate individuals and exceptions (1997b). The barred owl has a broad geographic range that includes four subspecies, encompasses most of the eastern half of North America (NA), and is currently spreading east to west across southern Canada and parts of the northern United States (US) (Johnsgard 1988; Livezey 2007; Livezey 2009a; Livezey 2009b; Mazur and James 2000). Therefore, generalities on size and age variation are likely to have errors (Carpenter 1992; Mueller 1990; Pyle 1997a; Pyle 1997b). In order to ameliorate the complications associated with the broad range and lack of detailed knowledge on molt, three methods of aging were used. The barred owls in this study were all of the subspecies Strix varia varia.

Beginning in January 2011, 44 of the 59 barred owls admitted to AH between October 2010 and March 2011 were aged ( 15 of the 59 had been cremated or released before January and therefore were not available for participation). Ten flight feather measurements (five on the left side and five on the right) were recorded and compared to values reported in Pyle 1997a for relative flight feather characteristics such as the juvenal feathers tending to have narrower, more plentiful flight feather barring compared to those of

Table 1. Barred Owl Admissions to Avian Haven.

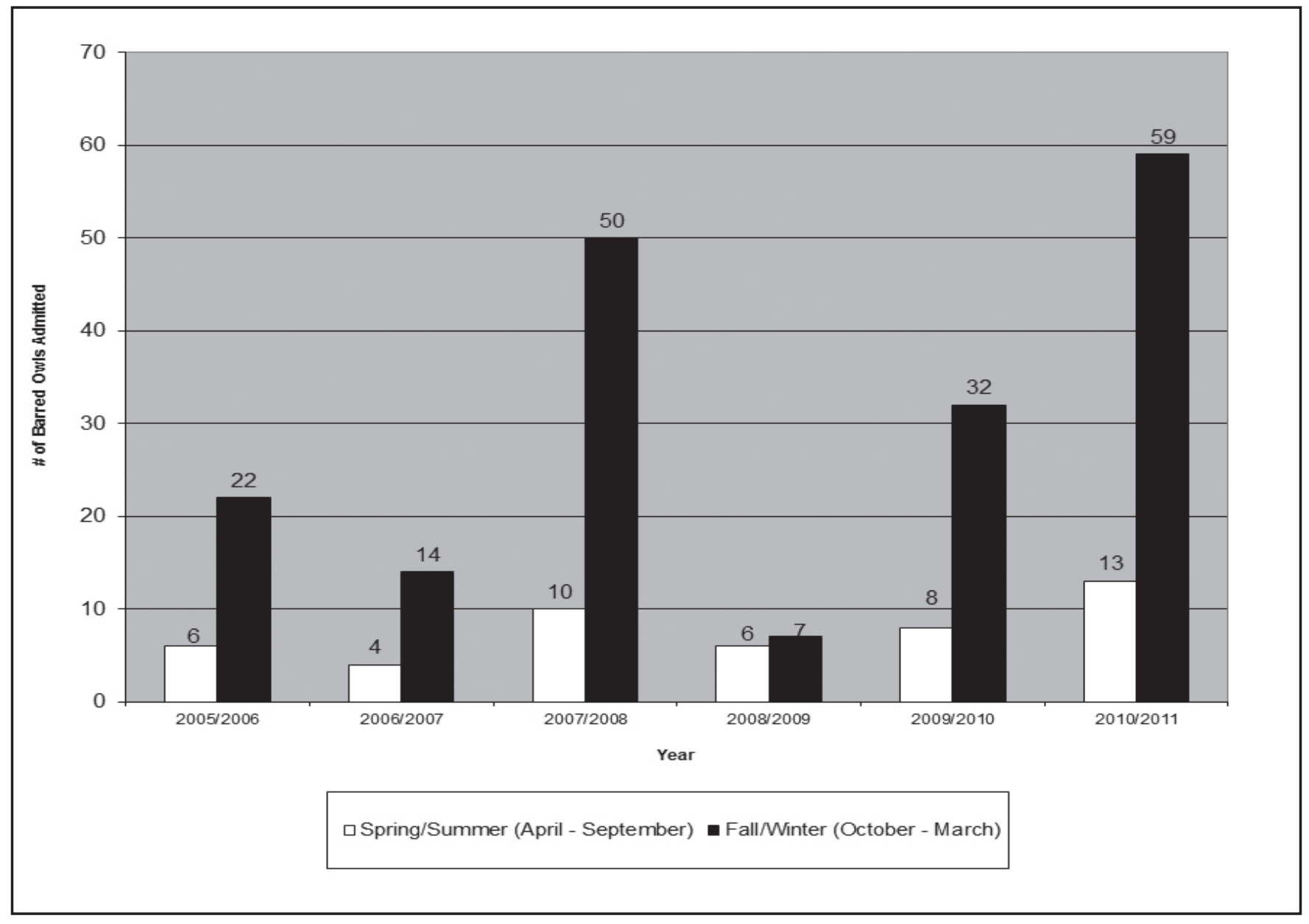


adults. On the basis of these measurements, the age of each individual was recorded as hatch-year/secondyear (HY/SY), referring to a juvenile that hatched in the 2010 breeding season, or after hatch-year/aftersecond-year (AHY/ASY), referring to an adult bird that hatched in the 2009 breeding season or earlier. In the 2010 calendar year, the bird was labeled HY if a juvenile or AHY if an adult, and as of 1 January 2011, the same individuals progressed to the next age category, SY or ASY, respectively. When recording ages of the owls using these measurements, HY/SY or AHY/ASY was recorded only in cases in which at least two of the five measurements on each side supported this age class and no measurements supported a different age class. Because the five measurement categories had overlapping ranges of values between the two age classes, many of individual measurements had to be recorded as inconclusive (or not applicable for birds that had damaged feathers needed for particular measurements). Inconclusive was recorded if only one measurement indicated a particular age class or when different measurements indicated conflicting age classes.

To distinguish between HY/SY and AHY/ASY individuals, the second aging method consisted of using evidence of more than one generation of flight feathers (or the lack thereof) based on color and length contrasts between adjacent feathers. This technique was used in conjunction with flight feather characteristics such as the shape and color of the tips of the primary and rectrice feathers (Duffy and Kerlinger 1992; Forsman 1981; Mazur and James 2000; Moen et al 1991; Pyle 1997a; Pyle 1997b).

The third method utilized the fluorescence of porphyrin pigments in the plumage, a technique previously used predominantly in northern saw-whet (Aegolius acadicus) and barn owls (Tyto alba). The porphyrin pigments in owl feathers fluoresce a dark pinkish-red under an ultraviolet light when new, but are degraded by exposure to sunlight (Clark 2004; McGraw 2006; Rück et al 1990; Weidensaul et al 2011; With 1978). An ultraviolet light source, in the form of a black light, was shone on the undersides of the wings (an area protected from direct sunlight), and the relative ages of the feathers compared in order to differentiate between HY/SY and AHY/ASY individuals (Weidensaul et al 2011).

More detail about the aging techniques used in this study may be found in Berry 2011.

\section{RESULTS}

A total 231 barred owls were admitted into $\mathrm{AH}$ in the six years running from April 2005 through March 2011. In the fall and winter months (October-March), 184 birds were admitted, whereas only 47 were admitted in the spring and summer months (AprilSeptember). Nestling admissions were not included in the data set. A one-way chi square $\left(\mathrm{X}^{2}\right)$ was performed to test the significance of this discrepancy; $X^{2}$ $=81.251, \mathrm{df}=1, \mathrm{p}<0.001$.

In all six years surveyed, more frequent admissions occurred during the fall and winter months than in the spring and summer months. However, this discrepancy varied from almost nonexistent (a difference of only a single owl between the two halves of the year) in April-March of 2008/2009, to a discrepancy of 46 owls between the two halves of April-March of 2010/2011 (Table 1). A one-way X² was calculated for the yearly seasonal admittance records for all six years for the fall and winter data and again, separately, for the spring and summer data. For the former, $\mathrm{X}^{2}=$ 68.19 with $\mathrm{df}=5, \mathrm{p}<0.0001$; however for the latter, $\mathrm{X}^{2}=6.74$ with $\mathrm{df}=5, \mathrm{p}=0.24$, a difference that is not statistically significant.

Among the admissions during the fall/winter season of 2010/2011, 44 owls were aged. In aging these owls, the flight feather measurements method yielded $20 \mathrm{HY} / \mathrm{SY}, 10 \mathrm{AHY} / \mathrm{ASY}$, and 14 birds whose age could not be determined conclusively. When comparing results of the three aging methods, it is important to note that the large number of owls aged as inconclusive by flight feather measurements method (14) all were based in some way on the same discrepant tail measurement (Figure 1). The feather characteristics method yielded $30 \mathrm{HY} / \mathrm{SY}, 13 \mathrm{AHY} / \mathrm{ASY}$, and only one bird whose age could not be determined conclusively (Figure 2a and 2b). All of the owls aged using the porphyrin fluorescence method yielded conclusive age rankings; $30 \mathrm{HY} / \mathrm{SY}$ and $14 \mathrm{AHY} / \mathrm{ASY}$ (Figure 3a and $3 \mathrm{~b}$ ). All conclusive age values given by the flight feather measurements, feather characteristics, and porphyrin fluorescence aging methods were in agreement with one another. Furthermore, in all cases, at least two of the methods used yielded conclusive results, suggesting that barred owls can indeed be aged reliably via fluorescence of porphyrin pigments in their feathers. A one-way $\mathrm{X}^{2}$ was applied to the $30 \mathrm{HY} / \mathrm{SY}$ and $14 \mathrm{AHY} / \mathrm{ASY}$ owls, assuming a null hypothesis of equal proportions $\mathrm{AHY} / \mathrm{ASY}$ grouping includes all adult owls of many different ages, therefore the overall population of barred owls in the study area should include a higher number of AHY/ASY than of HY/SY birds. However, since HY/SY barred owls 


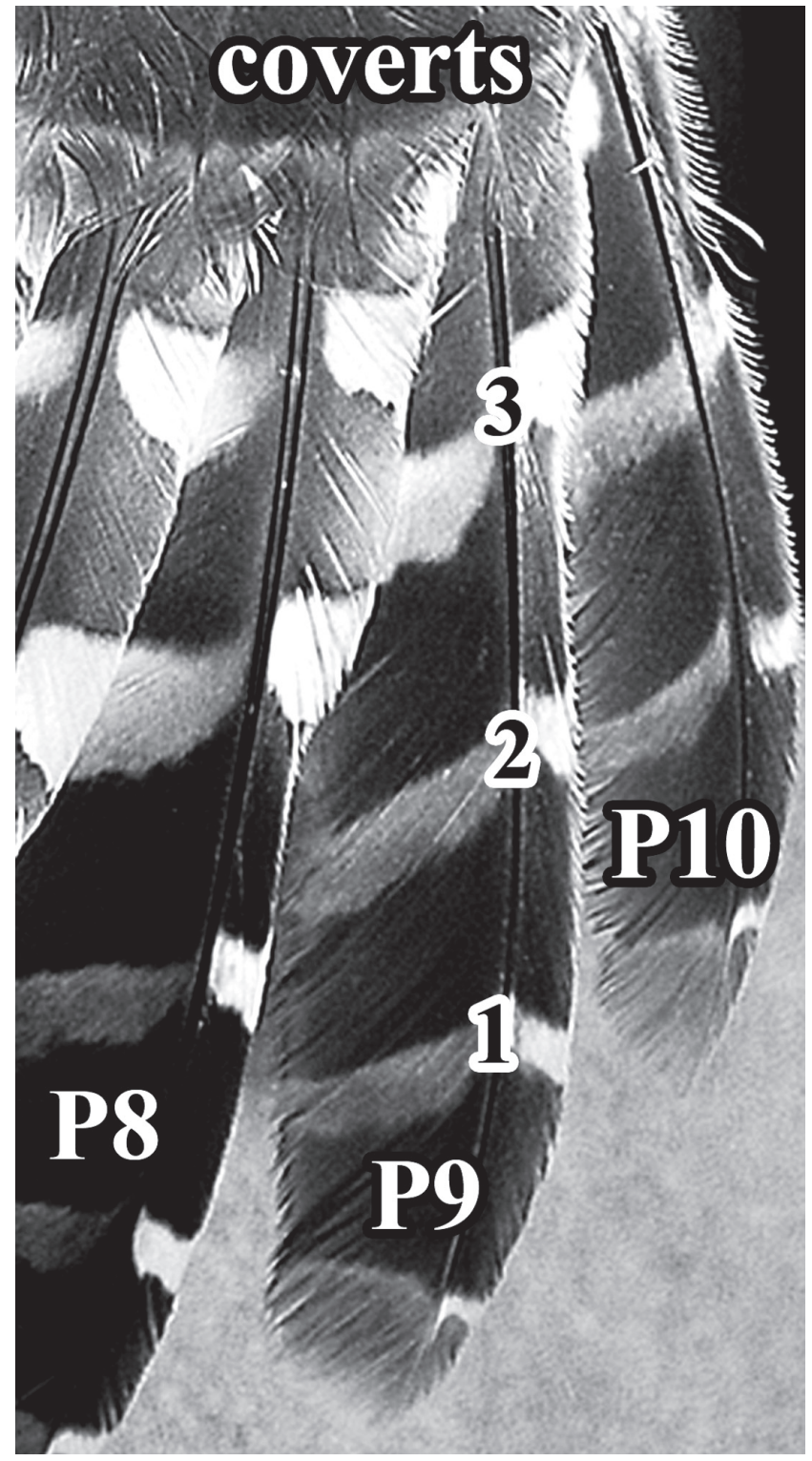

Figure 1. The flight feather measurements aging method uses calculations such as counting the number of pale bars (not including the tip) below the coverts on the ninth primary feather (P9). In this case there are three pale bars indicating this is an AHY/ASY barred owl.

are dispersing beginning in the fall, it is possible that an increased number of HY/SY birds could have been in the study area at this time in the form of dispersing owls from other populations, such as birds dispersing from Canada. An expected proportion of $0.5 \mathrm{HY} / \mathrm{SY}$ and 0.5 AHY/ASY owls was used; in doing so, it was assumed that the discrepancy between the local population of barred owls being more heavily weighted toward adult owls was offset by the increased numbers of immigrant HY/SY birds in the area. If dispersal from other areas turns out not to be a factor, using these expected proportions should produce the most conservative $\mathrm{X}^{2}$ value possible. Applied to this discrepancy, $X^{2}=5.818, d f=1, p=0.016$.

\section{Discussion}

The results of this study support the hypotheses stated in the introduction. Barred owl admissions in central Maine are statistically greater in the fall and winter months than in the spring and summer months. There is yearly variation in the fall and winter admissions, but little variation in the spring and summer. Furthermore, a significant number of the fall and winter admissions in 2010/2011 were HY/SY birds. The correlation between the large number of barred owls admitted in the fall and winter months and the large number of HY/SY birds admitted in this time suggests that, as HY/SY birds disperse in the fall and winter, their lack of experience results in large numbers of dispersing barred owls becoming injured in fall and winter months in years when the breeding season is successful (especially when followed by a winter with tightly packed or especially deep snow, in which the owls are more likely to use snow-free zones like roads as dispersal corridors), and smaller numbers of dispersing birds injured in years with less successful breeding seasons and/or milder winters.

In testing the hypotheses for this study, it was appropriate simply to distinguish between HY/SY and AHY/ASY owls. Similarly, in most rehabilitation settings, it is appropriate to age post-fledging barred owls using only these two general age categories. This basic age information is important in determining which birds need to be returned to their home territories for release in the fall and winter (AHY/ASY birds), and which birds do not need to be released where they were found, but instead could potentially fare better if released in suitable habitat without a resident pair already in attendance (HY/SY birds). Additionally, an age determination may help rehabilitators decide which non-releasable birds are good candidates for placement.

In evaluating the corollary to the final hypothesis (that barred owls can reliably be aged via the porphyrin fluorescence method), comparisons were made among data collected using flight feather measurements, flight feather characteristics, and porphyrin fluorescence methods of aging in a rehabilitation setting. Pyle (1997b) recommends that measurements and information on feather characteristics used for aging birds be gathered immediately after a bird's capture so that any plumage damage incurred from being in a captive setting does not confound the resulting classification. This recommendation becomes especially important in late winter/early spring when plumage damage incurred by normal wear and tear can make subtle differences in feather characteristics harder to detect, and cause data from measurements to be less accurate. It 


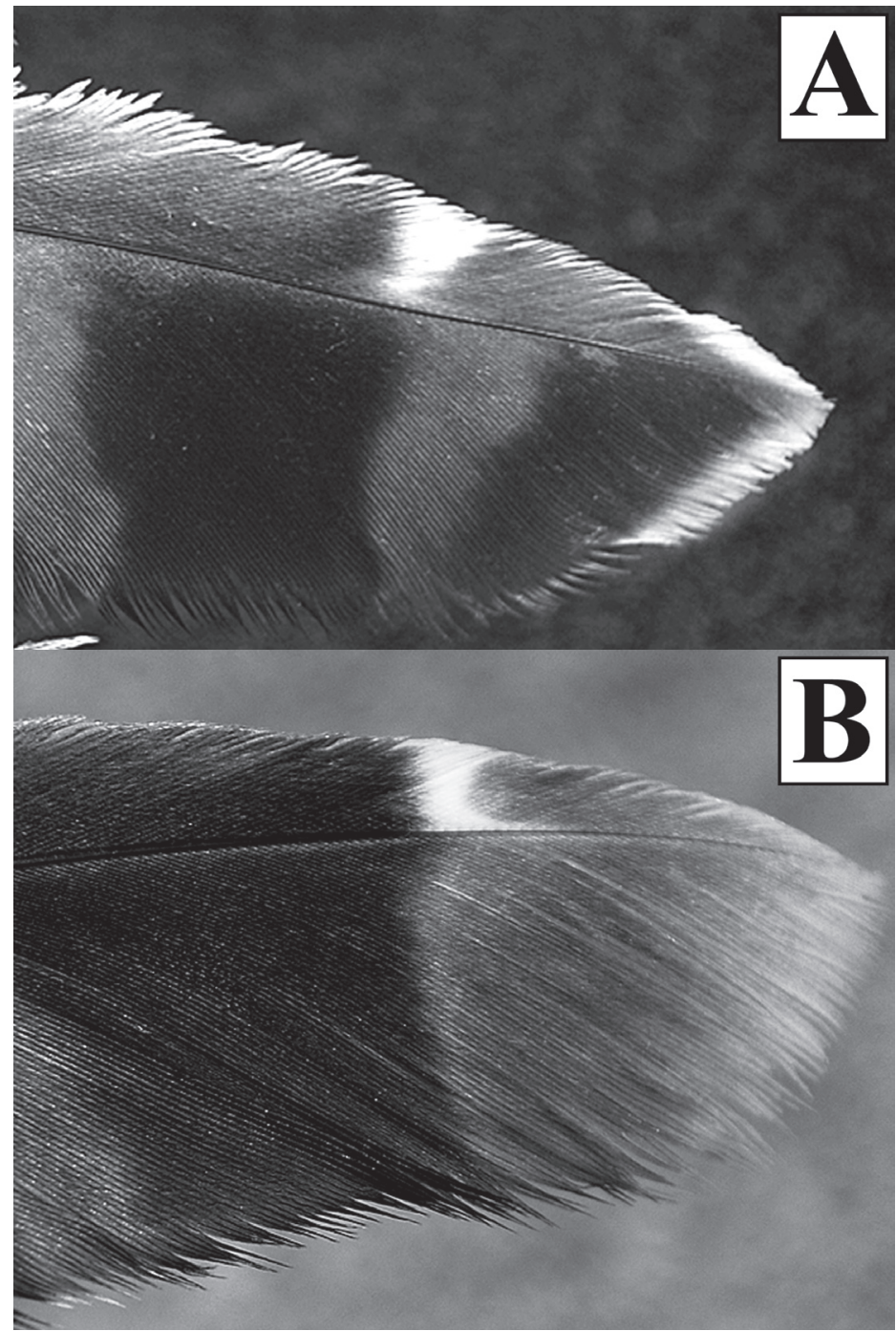

Figure 2. The feather characteristics aging method uses attributes of the flight feathers, which are different between juvenal and adult plumage. A. This is the tip of a juvenal primary feather (P9). It shows the pointy tip and white terminal stripe indicating this is a HY/SY barred owl. B. This is the tip of an adult primary feather (P9). It exhibits a wider, less tapered tip that ends in a large smudged pale bar indicating this is an AHY/ASY barred owl.

is a plausible recommendation for banders, but one rarely practical for birds aged in a rehabilitation center; feather measurements are not the first priority in an intake exam. Despite the fact that the owls examined for this study were aged after some period of time in captivity, all conclusive values from the three aging methods were in agreement with one another, and at least two of the aging methods yielded conclusive results for every bird examined. This agreement suggests that, time since capture notwithstanding, flight feather measurements and characteristics were adequate for evaluating the accuracy of the porphyrin fluorescence method. Furthermore, the large number of owls (14) aged as inconclusive by the flight feather measurements method were all, at least in part, due to a single discrepant tail measurement. This discrepancy may be due to a variation in this value in the part of the barred owls' geographic range covered by this study. In order to eliminate these inconclusive results, and potentially lend further support to the accuracy of the results gathered using the porphyrin fluorescence method, this tail measurement may need to be recalculated for this part (Northeast US or Maine) of the owls' range It is also possible that this and other specific measurements made using this method have similar variations across the geographic range and therefore the method could need a variety of recalculations in order for all values to be accurate for all parts of the range and/or for all subspecies. Due to the discrepancy in values gathered using this method, it is recommended that it only be used in conjunction with one or more of the other methods, unless these values are recalculated for the specific part of the geographic range from which a particular set of owls are being examined..

Feather damage from captivity or general seasonal wear and tear does not appear to affect the results garnered by the porphyrin fluorescence method (other than reducing the brightness of the fluorescence); therefore, using a black light to look at the fluorescence on the underside of the wings appears to be the most useful way to accurately and expediently age barred owls. However, care should be taken if this method is used exclusively, as barred owls do sometimes undergo a complete molt-more often than in the closely related northern spotted owl (Strix occidentalis caurina) (Forsman 1981; Mazur and James 2000; Pyle 1997a; Pyle 1997b)-and it is likely that most of these early molts occur in the more southern parts of their range. Data comparing the fluorescence of juvenal flight feathers with those of adult owls having undergone a complete molt are needed. If it is possible to differentiate between these two categories using the porphyrin fluorescence method, then barred owls could be accurately and quickly aged using only this method. Until such a comparison is made, however, it is recommended that porphyrin fluorescence be used in conjunction with some flight feather characteristics for best results, especially in the southern parts of the barred owls' range. Rehabilitators without direct access to Pyle (1997a; 1997b) may benefit from information in a booklet prepared by the author (Berry 2011). The possibility of a second-year bird that did not molt any flight feathers was not explored in this study (although the amount of feather abrasion and a lack of fluorescence should, in theory, be useful 


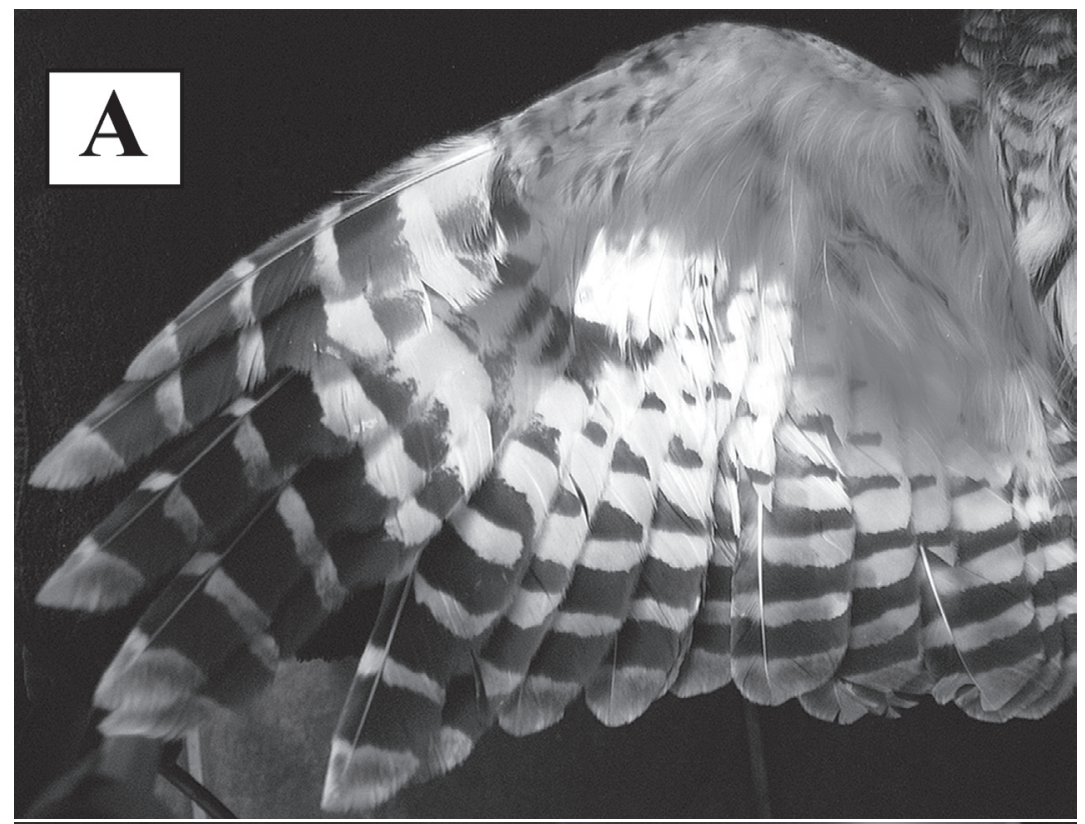

barred owl admittance numbers in the fall and winter records and the large, and potentially variable, number of $\mathrm{HY} / \mathrm{SY}$ owls admitted at this time of year. The discrepancy in the yearly fall and winter admissions could be, almost exclusively, related to the number of dispersing juveniles and the difference in the year-toyear conditions that these juveniles face, and have little to do with variations in the adult population. The effects of the increased metabolic demands associated with a HY/SY bird's combined search for a territory and food (in unfamiliar surroundings) should be studied to examine the possibility that dispersing birds that find a territory early in the fall and winter survive better than those that take longer. Rehabilitation centers making use of the porphyrin fluorescence aging method may hold important keys to understanding molt and the stratification of ages in populations of these silent, nocturnal hunters.

\section{ACKNOWLEDGEMENT}

The author would like to thank Diane Winn for her generous help in commenting on and editing various stages of this article and also the entire staff at Avian Haven, particularly Diane Winn, Marc Payne, and Shelley Spanswick for use of their records, resources, and especially their support. For taking time to answer specific questions on aging techniques, the author also would like to thank Kara Kristjanson, Peter Pyle, and Scott Weidensaul.

Figure 3. The porphyrin fluorescence aging method makes use of a black light shown on the underside of the wings of a barred owl in order to compare the relative ages of the individual wing feathers.

A. The contrast between adjacent feathers with and without fluorescence indicates this individual has multiple generations of wing feathers. This means this individual is an AHY/ASY barred owl.

$B$. The even fluorescence across this individual's wing feathers indicates this is a HY/ SY barred owl.

\section{PRODUCT INFORMATION}

Black lights may be purchased or ordered from many online distributors.

\section{LiterATURE CITED}

in identifying such an individual, should one exist). In addition to the simplistic age differentiation possible with the porphyrin fluorescence method, it should be noted that fluorescence has the potential to be used to age barred owls more precisely, and to help facilitate more detailed study into the molt and age classification of the barred owl across its geographic range. Further investigation is needed to explore the correlation between the larger and more variable

Belthoff, J. R., and G. Ritchison. 1989. Natal Dispersal of Eastern Screech-owls. Condor. 91: 254-265.

Berry, G. 2011. Aging Barred Owls in Rehabilitation Settings. Available from: <http://www.gloriberry.com/blog/wp-content/uploads/2012/01/ Aging-Barred-Owls-in-Rehabilitation-SettingsAutosaved.pdf>. 
Carpenter, T. W. 1992. Utility of Wing Length, Tail Length and Tail Barring in Determining the Sex of Barred Owls Collected in Michigan and Minnesota. Condor. 94:794-795.

Clark, G. A., Jr. 2004. Chapter 3: Form and Function: The External Bird. Pp. 3.1-3.70 in Handbook of Bird Biology (S. Podulka, R. W. Rohrbaugh, Jr., and R. Bonney, editors), 2nd edition. The Cornell Lab of Ornithology: Ithaca, NY.

Duffy, K., and P. Kerlinger. 1992. Autumn Owl Migration at Cape May Point, New Jersey. Wilson Bulletin. 104(2): 312-320.

Erritzoe, J. 2002. Bird Traffic Casualties and Road Quality for Breeding Birds. A Summary of Existing papers with a Bibliography. Available from: 〈www.birdresearch.dk>.

Forsman, E. D. 1981. Molt of the Spotted Owl. Auk. 98: 735-742.

Hamer, T. E., E. D. Forsman, and E. M. Glenn. 2007. Home Range Attributes and Habitat Selection of Barred Owls and Spotted Owls in an Area of Sympatry. Condor. 109: 750-768.

Hamer, T. E., D. I. Hays, C. M. Senger, and E. D. Forsman. 2001. Diets of Northern Barred Owls and Northern Spotted Owls in an Area of Sympatry. Journal of Raptor Research. 35(3): 221-227.

Hernandez, M. 1988. Road Mortality of the Little Owl (Athene noctua) in Spain. Journal of Raptor Research. 22(3): 81-84.

Holt, D. W., and C. Bitter. 2007. Barred Owl Winter Diet and Pellet Dimensions in Western Montana. Northwestern Naturalist. 88(1): 7-11.

Howell, S. N. G. 2010. Molt in North American Birds. Houghton Mifflin Harcourt: New York, NY.

Johnsgard, P. A. 1988. North American Owls. Smithsonian Institute Press: Washington, D.C.

Korschgen, L. J., and H. B. Stuart. 1972. Twenty Years of Avian Predator-Small Mammal Relationships in Missouri. Journal of Wildlife Management. 36(2): 269-282.

Livezey, K. B. 2007. Barred Owl Habitat and Prey: A Review and Synthesis of the Literature. Journal of Raptor Research. 41(3): 177-201.

Livezey, K. B. 2009a. Range Expansion of Barred Owls, Part I: Chronology and Distribution. American Midland Naturalist. 161: 49-56.

Livezey, K. B. 2009b. Range Expansion of Barred Owls, Part II: Facilitating Ecological Changes. American Midland Naturalist. 161: 323-349.
Loos, G., and P. Kerlinger. 1993. Road Mortality of Saw-whet and Screech-owls on the Cape May Peninsula. Journal of Raptor Research. 27(4): 210213.

Massemin, S., and Y. Handrich. 1997. Higher Winter Mortality of the Barn Owl Compared to the Long-eared Owl and the Tawny Owl: Influence of Lipid Reserves and Insulation? Condor. 99: 969-971.

Massemin, S., and T. Zorn. 1998. Highway Mortality of Barn Owls in Northeastern France. Journal of Raptor Research. 32(3): 229-232.

Mazur, K. M., and P. C. James. 2000. Barred Owl (Strix varia). The Birds of North America Online (A. Poole, editor). Ithaca, NY: Cornell Lab of Ornithology. Available from: <http://bna.birds. cornell.edu/bna/species508>.

Mazur, K. M., S. D. Frith, and P. C. James. 1998. Barred Owl Home Range and Habitat Selection in the Boreal Forest of Central Saskatchewan. Auk. 115: 746-754.

McGraw, K. J. 2006. Chapter 8: Mechanics of Uncommon Colors: Pterins, Porphyrins and Psittacofulvins. Pp. 354-398 in Bird Coloration (G. E. Hill and K. J. McGraw, editors), volume 1. Harvard University Press: Cambridge, MA.

Mead, C. 1997. Birds and Roads: Wilderness and Wildlife at Risk. From Lecture to the British Association for the Advancement of Science within the John Mason Conference of the British Ecological Society. Available from: <http://www. birdcare.com/bin/shownews/85>.

Moen, C. A., A. B. Franklin, and R. J. Gutiérrez. 1991. Age Determination of Subadult Northern Spotted Owls in Northwest California. Wildlife Society Bulletin. 19: 489-493.

Mueller, H. C. 1990. Can Saw-whet Owls be Sexed by External Measurements? Journal of Field Ornithology. 61(3): 339-346.

Nicholls, T. H., and D. W. Warner. 1972. Barred Owl Habitat Use as Determined by Radiotelemetry. Journal of Wildlife Management. 36(2): 213-224.

Postelli, K. 2000. Raptors and Roads. Wildlands CPR Road-RIPorter. 5(2). Available from: <http://www. wildlandscpr.org/node/257>.

Pyle, P. 1997a. Flight-feather Molt Patterns and Age in North American Owls. American Birding Association Monographs in Field Ornithology. No. 2. Pyle, P. 1997b. Identification Guide to North American Birds, volume I. Slate Creek Press: Bolinas, CA. 
Rück, A., C. Hildebrandt, T. Köllner, H.

Schneckenburger, and R. Steiner. 1990.

Competition Between Photobleaching and

Fluorescence Increase of Photosensitizing

Porphyrins and Tetrasulphonated

Chloroaluminiumphthalocyanine. Journal of

Photochemistry and Photobiology. 5(3-4): 311-319.

Ward, W. B. 1933. Owls on a Louisiana Highway.

Auk. 51(2): 236.

Weidensaul, C. S., B. A. Colvin, D. F. Brinker, and J. S. Huy. 2011. Use of Ultraviolet Light as an Aid in Age Classification of Owls. Wilson Bulletin. 123(2): 373-377.

With, T. K. 1978. On Porphyrins in Feathers of

Owls and Bustards. International Journal of

Biochemistry. 9(12): 893-895. (Nख

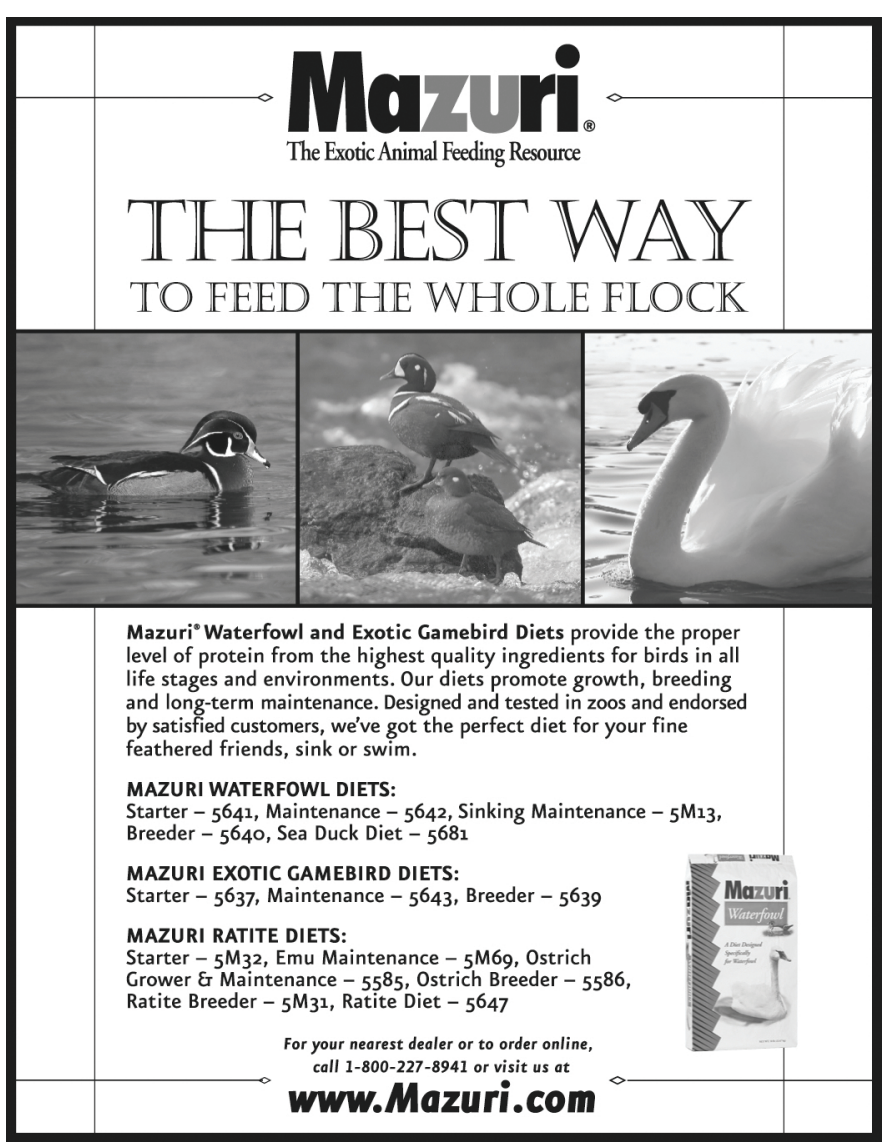

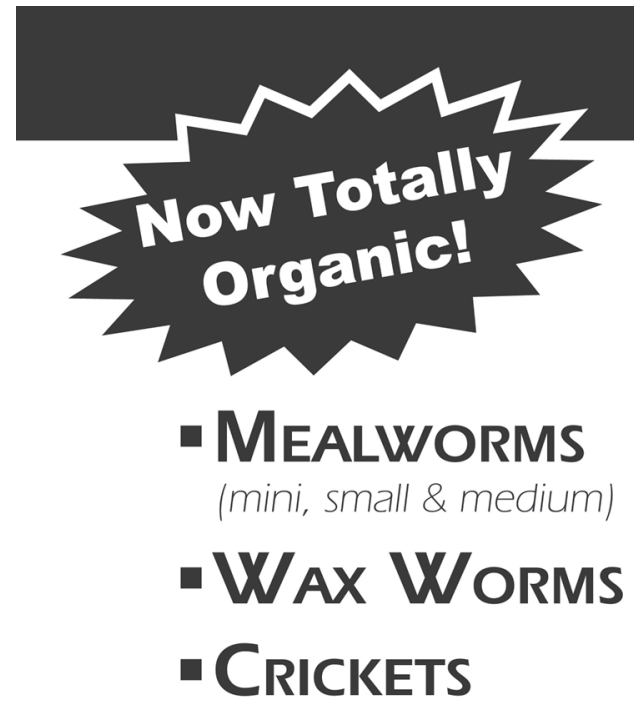

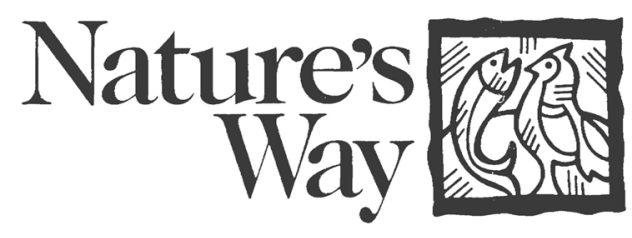

- Mealie Snax (roasted mealworms)

\section{- Wax Snax}

(roasted wax worms)

\section{Live Delivery Guaranteed!}

\section{Call Us Toll-free 1-800-31 8-2611}

FOR OUR FREE BROCHURE

Email: info@thenaturesway.com unw.thenaturesway.com
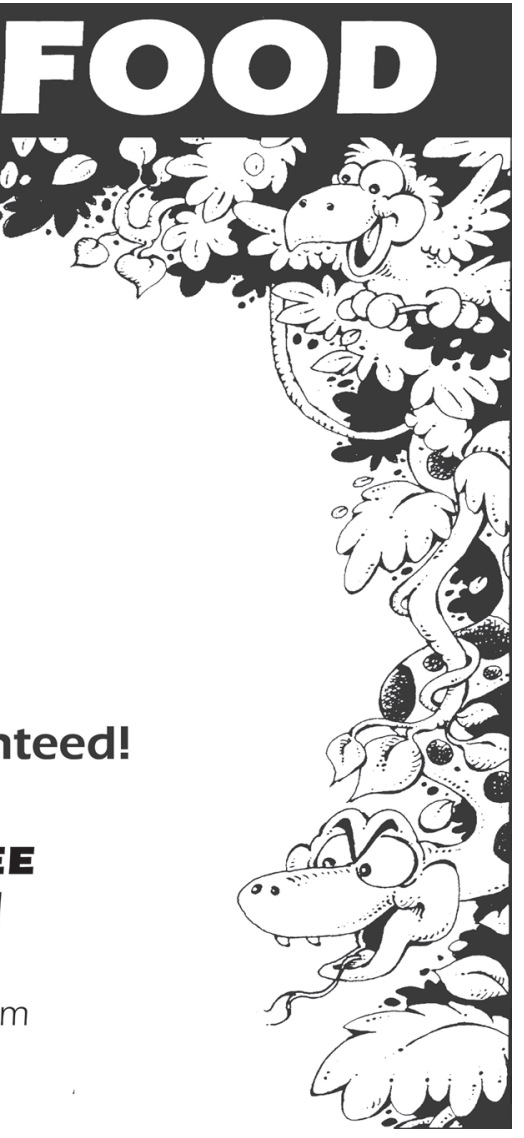